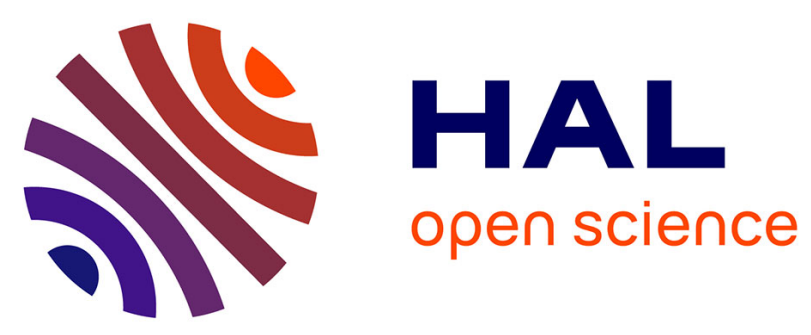

\title{
Evidences of an intermediate rodlike defect during the transformation of 113 defects into dislocation loops
}

\author{
S. Boninelli, Nikolay Cherkashin, Alain Claverie, Fuccio Cristiano
}

\section{To cite this version:}

S. Boninelli, Nikolay Cherkashin, Alain Claverie, Fuccio Cristiano. Evidences of an intermediate rodlike defect during the transformation of 113 defects into dislocation loops. Applied Physics Letters, 2006, 89 (16), pp.161904. 10.1063/1.2361178 . hal-01736076

\section{HAL Id: hal-01736076 https://hal.science/hal-01736076}

Submitted on 23 Mar 2018

HAL is a multi-disciplinary open access archive for the deposit and dissemination of scientific research documents, whether they are published or not. The documents may come from teaching and research institutions in France or abroad, or from public or private research centers.
L'archive ouverte pluridisciplinaire HAL, est destinée au dépôt et à la diffusion de documents scientifiques de niveau recherche, publiés ou non, émanant des établissements d'enseignement et de recherche français ou étrangers, des laboratoires publics ou privés. 


\section{Evidences of an intermediate rodlike defect during the transformation of $\{113\}$ defects into dislocation loops}

S. Boninelli, N. Cherkashin, A. Claverie, and F. Cristiano

Citation: Appl. Phys. Lett. 89, 161904 (2006); doi: 10.1063/1.2361178

View online: https://doi.org/10.1063/1.2361178

View Table of Contents: http://aip.scitation.org/toc/apl/89/16

Published by the American Institute of Physics

\section{Articles you may be interested in}

$\{311\}$ defects in silicon: The source of the loops

Applied Physics Letters 73, 3748 (1998); 10.1063/1.122882

Transmission electron microscopy on $\{113\}$ rodlike defects and $\{111\}$ dislocation loops in silicon-implanted silicon Journal of Applied Physics 82, 601 (1997); 10.1063/1.365587

Novel silicon phases and nanostructures for solar energy conversion

Applied Physics Reviews 3, 040807 (2016); 10.1063/1.4961724

Modeling and experimental characterization of stepped and $v$-shaped $\{311\}$ defects in silicon Journal of Applied Physics 115, 143514 (2014); 10.1063/1.4871538

Microstructural evolution of $\{113\}$ rodlike defects and $\{111\}$ dislocation loops in silicon-implanted silicon Applied Physics Letters 71, 659 (1997); 10.1063/1.119821

A topological point defect regulates the evolution of extended defects in irradiated silicon Applied Physics Letters 98, 171915 (2011); 10.1063/1.3585656

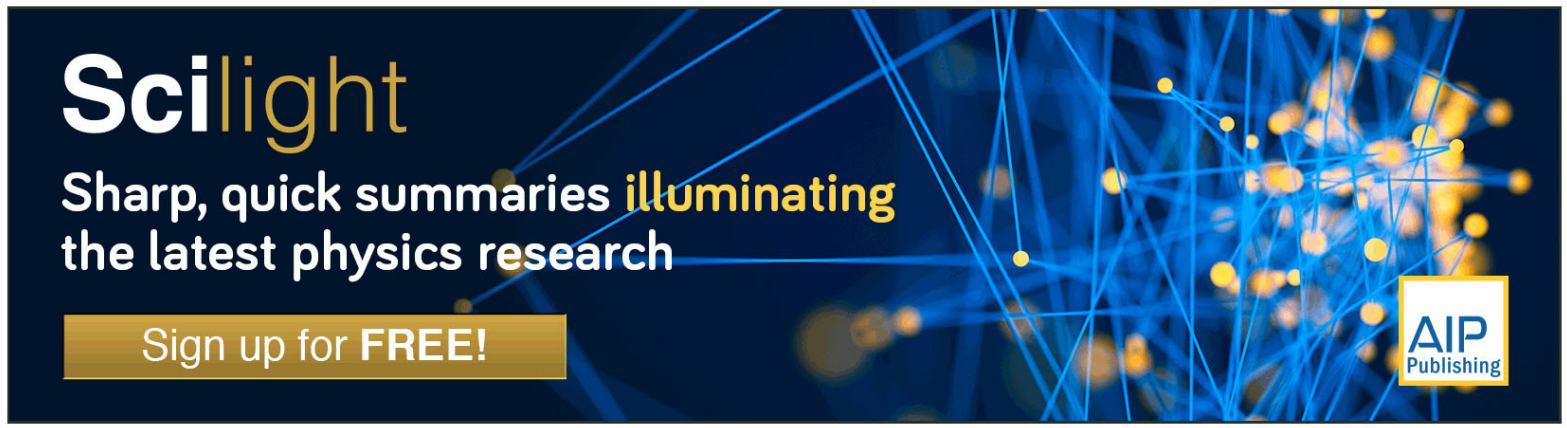




\title{
Evidences of an intermediate rodlike defect during the transformation of $\{113\}$ defects into dislocation loops
}

\author{
S. Boninelli, ${ }^{a)}$ N. Cherkashin, and A. Claverie \\ CEMES-CNRS, 29 Rue Jeanne Marvig, 31055 Toulouse, France \\ F. Cristiano \\ LAAS-CNRS, 7 Avenue du Colonel Roche, 31077 Toulouse, France
}

(Received 19 May 2006; accepted 25 August 2006; published online 16 October 2006)

\begin{abstract}
A detailed study of the transformation of the $\{113\}$ defects into dislocation loops has been carried out in Ge preamorphized silicon $\left(30 \mathrm{keV}, 1 \times 10^{15} \mathrm{Ge}^{+} / \mathrm{cm}^{2}\right)$ and annealed at $800{ }^{\circ} \mathrm{C}$ for time ranging from 15 to $2700 \mathrm{~s}$. The presence of a stable defect, along the $\langle 110\rangle$ directions, formed during the transformation from \{113\}'s into Frank dislocation loops (FDLs), has been revealed and studied. Performing a detailed transmission electron microscopy analysis in nonconventional zone axes, a $1 / 3$ [111]-type Burgers vector has been found. These defects are shown to be more stable than \{113\}'s but less than FDLs. (C) 2006 American Institute of Physics. [DOI: 10.1063/1.2361178]
\end{abstract}

The progress of the semiconductor industry is driven by the continuous miniaturization of complementary metaloxide semiconductor devices. In particular, this requires shallow and highly activated source-drain extension junctions. It has been demonstrated that preamorphization followed by dopant implantation can be used to reduce the junction's depth for $p$-type MOS devices. By employing the transmission electron microscopy (TEM), the crystallographic structure of the defects, formed during the low temperature epitaxial regrowth, has been resolved and to date four types of extended defects in $\mathrm{Si}$ are known: small interstitial clusters (less than ten atoms, invisible by TEM), elongated or rodlike defects, called $\{113\}$ 's, and perfect and faulted dislocation loops (PDLs and FDLs, respectively). ${ }^{1-4}$ It has been ascertained that, during annealing, all these defects evolve following an Ostwald ripening process and, eventually, they change their crystallographic structure, in order to minimize their formation energy. ${ }^{4}$

During a moderate thermal annealing $\left(600-800{ }^{\circ} \mathrm{C}\right)$, $\{113\}$ 's are initially formed. However, if the total interstitial population is sufficiently high, additional thermal budgets allow the $\{113\}$ 's to transform into PDLs and FDLs, which, in turn, engage a competitive ripening mechanism among themselves, depending on the different experimental conditions. $^{5-7}$ A particular attention has been paid to the evolution kinetics of extended defects, resulting from nonamorphizing $^{8,9}$ and amorphizing ${ }^{6-10}$ implants. In both cases it was concluded that nucleation of PDLs and FDLs is the result of an unfaulting process of the $\{113\}$ defects. $^{7-9}$

In this letter, we report a detailed study of the defect evolution after a preamorphizing implant, in which we show that an "intermediate" rodlike defect forms during the transformation of $\{113\}$ 's into DLs.

For our experiment Czochralski-grown $\langle 100\rangle$-oriented silicon wafers were implanted with $30 \mathrm{keV}, 1$ $\times 10^{15} \mathrm{Ge}^{+} / \mathrm{cm}^{2}$ ions. Following implantation, samples were annealed in $\mathrm{N}_{2}$ ambient in a Mattson rapid thermal process-

\footnotetext{
a) Author to whom correspondence should be addressed; also at MATIS CNR-INFM and Dipartimento di Fisica ed Astronomia, Università di Catania, Via Santa Sofia 64, 95123 Catania, Italy; electronic mail: simona.boninelli@cemes.fr
}

ing (RTP) system at $800{ }^{\circ} \mathrm{C}$ for times ranging from 15 to $2700 \mathrm{~s}$.

A $200 \mathrm{keV}$ JEOL 2010-HC TEM was used for the defect analysis, performed under weak beam dark field (WBDF) conditions. In Fig. 1 we report four plan-view images of samples annealed at $800{ }^{\circ} \mathrm{C}$ for $15 \mathrm{~s}$ (a), $120 \mathrm{~s} \mathrm{(b),} 300 \mathrm{~s}$ (c), and $2700 \mathrm{~s}(\mathrm{~d})$. Images have been taken under the imaging condition of $\mathbf{g}=400$ [the arrow in (a) indicates the direction of the diffraction vector as seen on the corresponding diffraction pattern]. Figure 1(a) shows that after $15 \mathrm{~s}$ only rodlike defects are formed (no DLs). The vast majority of the observed defects are elongated on the [010] direction, perpendicular to the diffracting $\mathbf{g}$ vector. In addition, few defects, labeled A and B in Fig. 1(a), are elongated along [110] and [-110] directions (i.e., at $45^{\circ}$ with respect to the $\mathbf{g}$ vector).

The diffraction contrast theory predicts that the visibility of a defect depends mainly on $\mathbf{g} \cdot \mathbf{b}$ and sligtly on $|\mathbf{g} \cdot \mathbf{b} \wedge \mathbf{u}|$ values, where $\mathbf{b}$ is the Burgers vector of the defect and $\mathbf{u}$ is a vector along the dislocation direction. ${ }^{11}$ According to theory, defects whose $\mathbf{g} \cdot \mathbf{b}$ value is higher than 0.64 are clearly detected. Takeda and Kohyama ${ }^{12}$ found the Burgers vector for $\{113\}$ 's equal to $a / 25\langle 116\rangle$, where $a$ is the Si lattice param-
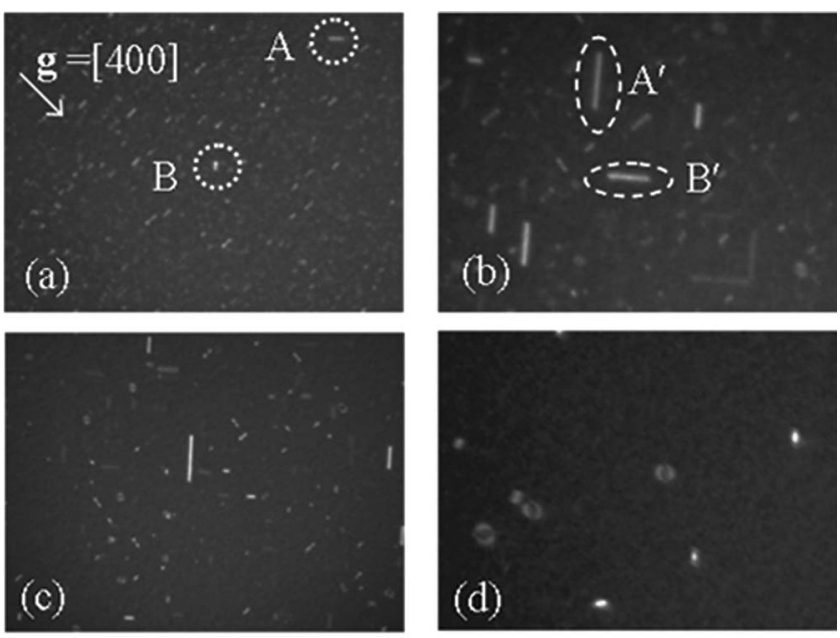

\section{$200 \mathrm{~nm}$}

FIG. 1. Plan-view TEM images of the extended defects, formed after $15 \mathrm{~s}$ (a), $120 \mathrm{~s} \mathrm{(b),} 300 \mathrm{~s}(\mathrm{c})$, and $2700 \mathrm{~s}(\mathrm{~d})$ annealing at $800{ }^{\circ} \mathrm{C}$. 

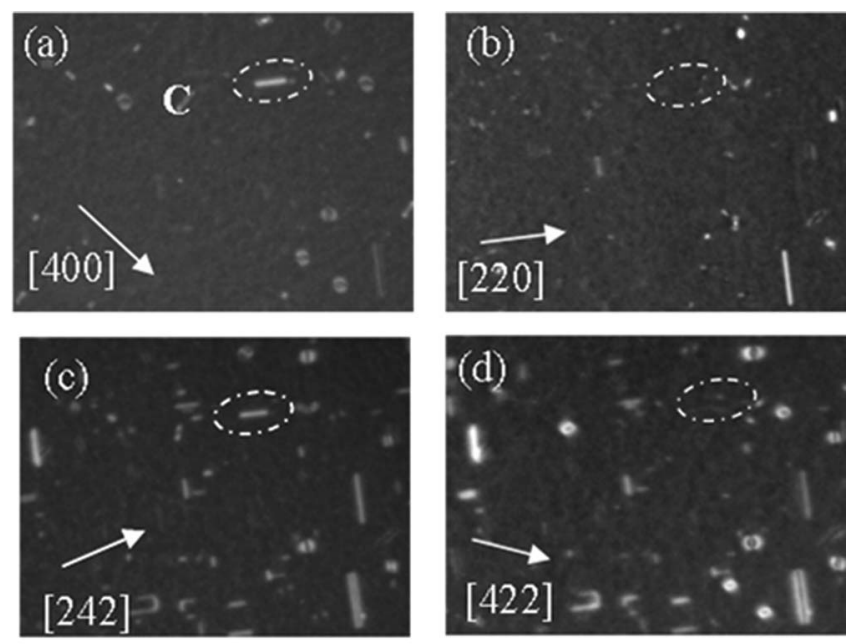

\section{$200 \mathrm{~nm}$}

FIG. 2. Plan-view TEM images taken with $\mathbf{g}=400$ (a), 220 (b), 242 (c), and 422 (d). The arrow indicates the corresponding $\mathbf{g}$ vector direction, as seen on the diffraction pattern.

eter. Carrying out the $\mathbf{g} \cdot \mathbf{b}$ and $|\mathbf{g} \cdot \mathbf{b} \wedge \mathbf{u}|$ products for the 12 Burgers vectors, associated with the 12 variants of $\{113\}$ 's, it is possible to demonstrate that not all the variants appear with the same contrast. In particular, when imaged with $\mathbf{g}$ $=400$, only four variants, whose projections on the image plane appear perpendicular to $\mathbf{g}$, are strongly visible because their $\mathbf{g} \cdot \mathbf{b}$ value, equal to about 0.96 , is high enough. On the other hand, the contrast exhibited by the remaining eight variants is vanishing, due the low $\mathbf{g} \cdot \mathbf{b}$ value (about 0.16 ). We can therefore conclude that all the defects perpendicular to $\mathbf{g}$, observed in Fig. 1(a), are indeed conventional $\{113\}$ defects.

In contrast, defects labeled $\mathrm{A}$ and $\mathrm{B}$ do not behave as conventional $\{113\}$ 's, owing to their unpredicted very high contrast. Thus, they must then have different crystallographic characteristics. In Fig. 1(b) the image of a sample annealed for 120 s presents many elongated defects still visible.

Similarly to the previous case, they consist of both conventional $\{113\}$ 's (projected along the [010] direction) and of unconventional elongated defects on the [110] and $[-110]$ directions (labeled $\mathrm{A}^{\prime}$ and $\mathrm{B}^{\prime}$ ). An image of sample annealed for $300 \mathrm{~s}$ is shown in Fig. 1(c). A reduction of the defect density and, furthermore, the appearance of a few FDLs is noticeable, although small \{113\}'s and, again, anomalous elongated defects are still detected. Finally, for the sample subjected to a $2700 \mathrm{~s}$ annealing, we notice a further reduction of the defect density and, at once, the transformation of all the defects into FDLs. These findings clearly indicate that an increasing thermal budget favors the transformation of $\{113\}$ 's into DLs; however, it is striking to note that "atypical" defects appear during the transformation. In order to elucidate their crystallographic characteristics and, in particular, to determine their Burgers vector, we have carried out a detailed TEM analysis on the sample annealed for $300 \mathrm{~s}$. Two diffracting vectors $\mathbf{g}$ were selected by tilting the sample in two different zone axes (i.e., [001] and [-1-13]).

As shown in Fig. 2, the rodlike defect, denoted by $\mathrm{C}$, shows high contrast for $\mathbf{g}=400$ and 242 [Figs. 2(a) and 2(c), respectively] and no contrast or residual contrast for $\mathbf{g}=220$ and 422 [Figs. 2(b) and 2(d), respectively]. The contrast of the $\mathrm{C}$ defect is proved to be residual for $\mathbf{g}=422$ as it does not depend on the sign of the $s$ deviation parameter. Taking into
TABLE I. $\mathbf{g} \cdot \mathbf{b}$ and $|\mathbf{g} \cdot \mathbf{b} \wedge \mathbf{u}|$ values as a function of various $\mathbf{g}$ vectors, evaluated for $\{111\}$-RLs and PDLs, characterized by $1 / 3[-111]$ and $1 / 2$ $[-110]$ Burgers vector, respectively.

\begin{tabular}{ccccc}
\hline \hline & $\mathbf{g}=\langle 400\rangle$ & $\mathbf{g}=\langle 220\rangle$ & $\mathbf{g}=\langle 242\rangle$ & $\mathbf{g}=\langle 422\rangle$ \\
\hline $\mathbf{g} \cdot \mathbf{b}\{111\}-\mathrm{RL}$ & 1.32 & 0 & 1.32 & 0 \\
$\mathbf{g} \cdot \mathbf{b} \wedge \mathbf{u}\{111\}-\mathrm{RL}$ & 0.93 & 0 & 0.47 & 1.4 \\
$\mathbf{g} \cdot \mathbf{b}(\mathrm{PDL})$ & 2 & 0 & 1 & 1 \\
$\mathbf{g} \cdot \mathbf{b} \wedge \mathbf{u}(\mathrm{PDL})$ & 0 & 0 & 1.41 & 1.41 \\
\hline \hline
\end{tabular}

account the behavior of the rodlike defect $\mathrm{C}$ as a function of the different $\mathbf{g}$ vectors, we found that a Burgers vector parallel to $[-111]$ can accurately explain the observed contrast. The contrast extinction observed with $\mathbf{g}=220$ means that $\mathbf{g} \cdot \mathbf{b}=0$ and $|\mathbf{g} \cdot \mathbf{b} \wedge \mathbf{u}|=0$ and, thus, the dislocation lines bounding the defect $\mathrm{C}$ are parallel to the [110] direction. The detected displacement field around such defects imposes that the Si interstitials form additional $\{111\}$ plane. Thus the atomic density in these defects is three times larger than in $\{113\}$ planes. It has to be noted that perfect DLs are also elongated along $\langle 110\rangle$ directions and, in some cases, can exhibit a sharp contrast, similar to rodlike defects. In order to avoid any ambiguity and prove that $\mathrm{C}$ defect is not a particular type of PDL, the $\mathbf{g} \cdot \mathbf{b}$ and $|\mathbf{g} \cdot \mathbf{b} \wedge \mathbf{u}|$ values expected in the case of a PDL elongated on the [110] direction are also reported as a comparison on Table I, where the known value of the Burgers vector for the PDL is taken equal to $1 / 2$ [-110]. As shown in Table I, if the $\mathrm{C}$ defect was a long conventional PDL, it should have been visible and exhibited the same contrast if imaged with $\mathbf{g}=242$ and 422 . On the contrary, a quick comparison of the $\mathrm{C}$ defect in Figs. 2(c) and 2(d) clearly reveals that it shows high contrast when imaged with $\mathbf{g}=242$ but only a residual contrast with $\mathbf{g}=422$ and, therefore, it cannot be a PDL. These evidences definitely prove that $\mathrm{C}$ is an example of a family of extended defects, elongated on the $\langle 110\rangle$ directions, with $\{111\}$ habit planes and $1 / 3\langle 111\rangle$ Burgers vectors. Hereafter we will refer to them as $\{111\}$-RL defects. ${ }^{13}$

A quantitative analysis of the defect evolution has been carried out and density, mean size, and $N_{b}$, i.e., concentration of trapped atoms on defects, are reported in Fig. 3 as a function of the annealing time. Concerning the density evolution of each type of defect, it is straightforward to note, from Fig. $3(\mathrm{a})$, that a continuous dissolution of $\{113\}$ 's occurs, which is definitely concluded after $2700 \mathrm{~s}$ annealing. On the other hand, the $\{111\}$-RL defect density increases, to some extent, until $300 \mathrm{~s}$ annealing then it tends to decrease. Finally, the FDL density remains almost constant even though a slight continuous increase is noticeable up to $2700 \mathrm{~s}$. These results indicate that, for low thermal budget, dissolution and transformation of $\{113\}$ 's induce the increase of $\{111\}-\mathrm{RL}$ and FDL densities. $\{111\}$-RLs are, in turn, dissolved or transformed into FDLs for longer thermal annealing.

As far as the evolution of the mean size in concerned, it is shown in Fig. 3(b) that the mean length of $\{113\}$ 's increases until $300 \mathrm{~s}$, then it tends to zero as they have dissolved for higher thermal budget. The initial increase of the $\{113\}$ mean size implies that, according to the Ostwald ripening process, dissolution starts with the disappearance of smaller defects, which are energetically less stable than the longer ones. The mean size of $\{111\}$-RLs is systematically slightly larger than that of $\{113\}$ 's and it is possible to distin- 


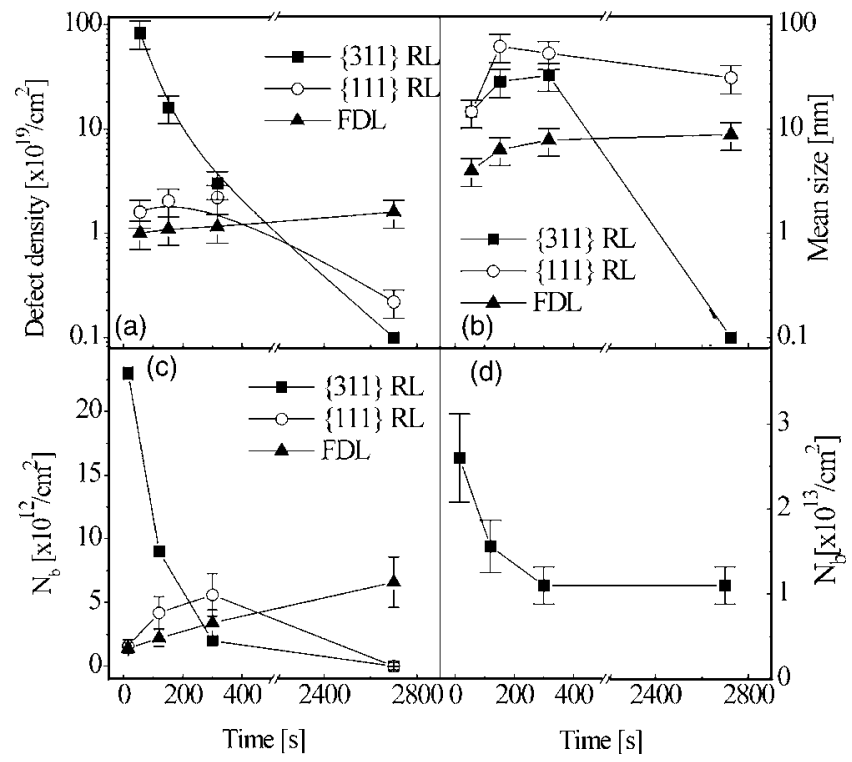

FIG. 3. Density (a), mean size (b), concentration of trapped interstitials in each type of defect (c), and concentration of trapped interstitials in whole defect population (d), as functions of the annealing time.

guish two different regimes. In the first stage, up to $120 \mathrm{~s}$, they grow and their mean length increases from about 15 to $60 \mathrm{~nm}$, then they tend to shrink down to about $30 \mathrm{~nm}$. A different trend is observed for the mean radius of FDLs, which systematically increases, even if slowly, indicating that they are continuously growing. The analysis of Fig. 3(c) reports the $N_{b}$ concentration of $\mathrm{Si}$ interstitials trapped on each class of defects. For this quantification we have assumed for both the $\{311\}$ 's and the $\{111\}$-RLs a constant width of $4 \mathrm{~nm}$ (i.e., independent on the defect length) and a thickness of a one crystal plane. It shows that after $15 \mathrm{~s}$ annealing most of the $\mathrm{Si}$ interstitials are trapped in the $\{113\}$ 's. After $300 \mathrm{~s}$ they are transferred to the $\{111\}$-RLs that contain the $50 \%$ of the total population, and, finally, for longer annealing times they are all stored in FDLs. These quantitative results are a further proof that the $\{111\}$-RLs are more stable than $\{113\}$ 's but less stable than FDLs and, therefore, these intermediate defects, appearing during the transformation of $\{113\}$ 's in FDLs, might be the "source" of FDLs. It is, therefore, proposed that the transformation of $\{113\}$ 's into dislocation loops is accomplished via nucleation of these intermediate defects.

Finally, in Fig. 3(d) the $N_{b}$ concentration of interstitials trapped in all the defects is reported as a function of the annealing time. An initial reduction of $N_{b}$ up to $300 \mathrm{~s}$ annealing is seen, while for longer times the amount of interstitials incorporated in the defects is stabilized. These results are in agreement with previous studies of the transformation on $\left\{113\right.$ \}'s into DLs. ${ }^{9}$ The net loss of atoms during the first $300 \mathrm{~s}$ is caused by the role played by the surface, which acts as a sink for the Si atoms released by the defects. However, for higher annealing time another competitive mechanism, which blocks the flux of interstitials towards the surface, prevails. Since it is known that FDLs are energetically stable and exhibit a very low interstitial emission rate, the percentage of FDLs, with respect to the total amount of defect population, has been evaluated as a function of the different annealing times. Initially, this value is about $0.01 \%$, then it rises to about $5 \%$ after $120 \mathrm{~s}$ to $20 \%$ after $300 \mathrm{~s}$ and, finally, almost the total defect population is constituted by FDLs after $2700 \mathrm{~s}$. These results suggest that, when the percentage of FDLs becomes significant in comparison with the other defect types, the system favors the interexchange of atoms between the defects themselves rather than their "migration" toward the surface and, hence, it is the presence of FDLs which constitutes the alternative-competitive interstitial sink.

In conclusion, the structure of defects observed in $\mathrm{Ge}$ amorphized and thermal annealed $\mathrm{Si}$ has been studied. In particular, a family of extended defects, called $\{111\}$-RL, elongated on the $\langle 110\rangle$ directions, with a $\{111\}$ habit plane and characterized by a Burgers vector equal to $1 / 3$ [111] has been detected. Moreover, the quantitative analysis of the thermal evolution of defects shows that an intermediate stage in the transformation of $\{113\}$ 's into FDLs exists, during which most of the interstitial atoms are stored in $\{111\}$-RLs. It is proposed that the transformation of $\{113\}$ 's into dislocation loops is accomplished via nucleation of these intermediate defects. Finally, a competitive mechanism between FDLs and the Si surface has been observed. In particular, when the percentage of FDLs in comparison with the whole population is negligible, dissolution with a net loss of interstitials towards the surface prevails. On the contrary, when this percentage becomes significant the loops act as trapping centers for the Si interstitials and, therefore, loss is prevented.

The authors thank S. Paul and W. Lerch of Mattson Thermal Products for performing the RTP annealing. This work was supported by the European integrated project NANOCMOS.

${ }^{1}$ D. J. Eaglesham, P. A. Stolk, H. M. Gossmann, and J. M. Poate, Appl. Phys. Lett. 65, 2305 (1994).

${ }^{2}$ S. Takeda, M. Kohyama, and K. Ibe, Philos. Mag. A 70, 287 (1994).

${ }^{3}$ B. de Mauduit, L. Laanab, C. Bergaud, M. M. Faye, A. Martinez, and A. Claverie, Nucl. Instrum. Methods Phys. Res. B 84, 190 (1994).

${ }^{4}$ A. Claverie, B. Colombeau, B. de Mauduit, C. Bonafos, X. Hebras, G. Ben Assayag, and F. Cristiano, Appl. Phys. A: Mater. Sci. Process. 76, 1025 (2003).

${ }^{5}$ C. Bonafos, D. Mathiot, and A. Claverie, J. Appl. Phys. 83, 3008 (1998). ${ }^{6}$ F. Cristiano, J. Grisolia, B. Colombeau, M. Omri, B. de Mauduit, A. Clavarie, L. F. Giles, and N. E. B. Cowern, J. Appl. Phys. 87, 820 (2000). ${ }^{7}$ F. Cristiano, N. Cherkashin, X. Hebras, P. Calvo, Y. Lamrani, E. Schedi, B. de Mauduit, B. Colombeau, W. Lerch, S. Paul, and A. Clavarie, Nucl. Instrum. Methods Phys. Res. B 216, 46 (2004).

${ }^{8}$ J. Li and K. S. Jones, Appl. Phys. Lett. 73, 3748 (1998).

${ }^{9}$ P. Calvo, A. Claverie, N. Cherkashin, B. Colombeau, Y. Lamrani, B. de Mauduit, and F. Cristiano, Nucl. Instrum. Methods Phys. Res. B 216, 173 (2004).

${ }^{10}$ L. S. Robertson, K. S. Jones, L. M. Rubin, and J. Jackson, J. Appl. Phys. 87, 2910 (2000).

${ }^{11}$ D. B. Williams and C. B. Carter, Imaging, Transmission Electron Microscopy Vol. 3 (Plenum, New York, 1996), 421.

${ }^{12}$ S. Takeda and M. J. Kohyama, Inst. Phys. Conf. Ser. 134, 33 (1993).

${ }^{13}$ Examples of these defects have already been seen in literature. In fact, Li and Jones (Ref. 8) performing in situ measurements, follow the thermal evolution of an elongated defect until its transformation into DLs and conclude that they are generated by a direct unfaulting process of $\{113\}$ 's. In that article, WBDF TEM images were taken with $\mathbf{g}=220$. With such imaging conditions, theory predicts that only eight variants of $\{113\}$ 's, whose projections are along the $[110]$ and $[-110]$ directions, perpendicular to each other, show appreciable contrast. In that aforementioned article, most of RL defects, shown in Fig. 1(a), are placed at $90^{\circ}$ with respect to each other. It is plausible to believe that their contrast behavior is typical of the visible families of $\{113\}$ 's, projected along the [110] and $[-110]$ directions. Nevertheless, the projection of the high contrast defect, chosen to follow in situ its thermal evolution, is elongated along the [100] direction. For the visibility reasons already explained in the text, we suspect that it is probably not a $\{113\}$ but, rather, the $\{111\}$-RL defect, evidenced in this letter. 